\title{
A dynamic price model based on levelized cost for district heating
}

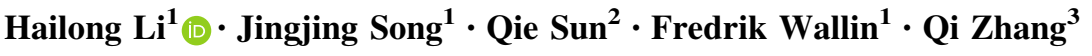 \\ ${ }^{1}$ School of Business, Society and Technology, Mälardalen University, PO Box 883, Västerås 72123, Sweden \\ ${ }^{2}$ Institute of Thermal Science and Technology, Shandong University, Jinan, China \\ ${ }^{3}$ China Petroleum University, Beijing, China
}

Received: 20 October 2018/Revised: 29 December 2018/Accepted: 3 January 2019/Published online: 14 January 2019

(C) The Author(s) 2019

\begin{abstract}
District Heating (DH) is facing a tough competition in the market. In order to improve its competence, an effective way is to reform price models for DH. This work proposed a new dynamic price model based on the levelized cost of heat $(\mathrm{LCOH})$ and the predicted hourly heat demand. A DH system in Sweden was used as a case study. Three methods were adopted to allocate the fuel cost to the variable costs of heat production, including (1) in proportion to the amount of heat and electricity generation; (2) in proportion to the exergy of generated heat and electricity; and (3) deducting the market price of electricity from the total cost. Results indicated that the LCOH-based pricie model can clearly reflect the production cost of heat. Through the comparison with other market-implemented price models, it was found that even though the marketimplemented price models can, to certain extent, reflect the variations in heat demand, they cannot reflect the changes in production cost when different methods of heat production are involved. In addition, price model reforming can lead to a significant change in the expense of consumers and consequently, affect the selection of heating solution.
\end{abstract}

Keywords District heating - Dynamic heat price . Levelized cost of heat · Heat demand · Price model
Abbreviations
CHP Combined heat and power
DEH Direct electrical heating
EDC Energy demand component
FOM Fixed operation and maintain cost

FDC Flow demand component

HP Ground source heat pump

LDC Load demand component

New-PM Subscription price model

Old-PM Seasonal price model

VOM Variable operation and maintain cost

COP Coefficient of performance

DH District heating

FGC Flue gas condensation

FCC Fixed connection component

HO Heat-only process in CHP plants

$\mathrm{LCOH} \quad$ Levelized cost of heat

M-1 3 Allocation methods for heat production in CHP plant

TIC Total investment cost

\section{Introduction}

According to the International Energy Agency (IEA), the energy used for space heating accounts for $10 \%$ of the world energy consumption and consequently a significant share of $\mathrm{CO}_{2}$ emissions (International Energy Agency 2018). In Europe, heating and cooling are responsible for approximately $50 \%$ of total final energy consumption. District heating (DH) alone reduces more than 110 million tons of $\mathrm{CO}_{2}$ emission annually, representing $2.6 \%$ of the union's annual $\mathrm{CO}_{2}$ emissions (DHC + Technology Platform 2020). Therefore, it is important to explore the potential of energy savings in this sector in order to mitigate climate change. 
DH is characterized as high energy efficiency and low environmental pollution among different methods of heating, especially in the context of Nordic area, whereas, it is facing tougher competition in the market, since other technologies have achieved great improvement, and hence lower costs, while the price of DH keeps rising. Taking the Swedish DH market as an example, the price in 2017 was increased by almost $60 \%$ compared to the level in 2001, as shown in Fig. 1. By contrast, the costs for other heating options, such as heat pumps and wood pellet boilers, stay on a relatively low level. For instance, heat pumps normally have a coefficient of performance (COP) of 3-5. During the same period aforementioned, the price for electricity was 800-950 SEK/MWh including tax, which implies that for a heat pump system, the cost for producing $1 \mathrm{MWh}$ heat is between 160 and 316 SEK.

A proper price model could give incentives to $\mathrm{DH}$ companies to upgrade the system and optimize the production in order to improve their competitiveness in the market ( $\mathrm{Li}$ et al. 2015). In the meantime, an effective price model could also contribute to energy savings and $\mathrm{CO}_{2}$ emission reduction, as price is the most important factor affecting consumers' behavior (Lin et al. 2017; Wang et al. 2018). Therefore, developing a proper price model is essential for encouraging heat demand response and enhancing sustainability of DH systems.

The objective of this work is to develop a new dynamic model based on the levelized cost of heat ( $\mathrm{LCOH})$ which can reflect the changes in production and fuel mix and eventually improve the competitiveness of DH. The contributions of this work to the research topic included:

- Analyzing the challenges faced by both DH companies and consumers and identifying the drawbacks of the currently market-implemented price models;

- Developing a novel dynamic price model based on $\mathrm{LCOH}$;

- Evaluating the impacts of the dynamic price model on consumers' energy expense and their possible reaction.

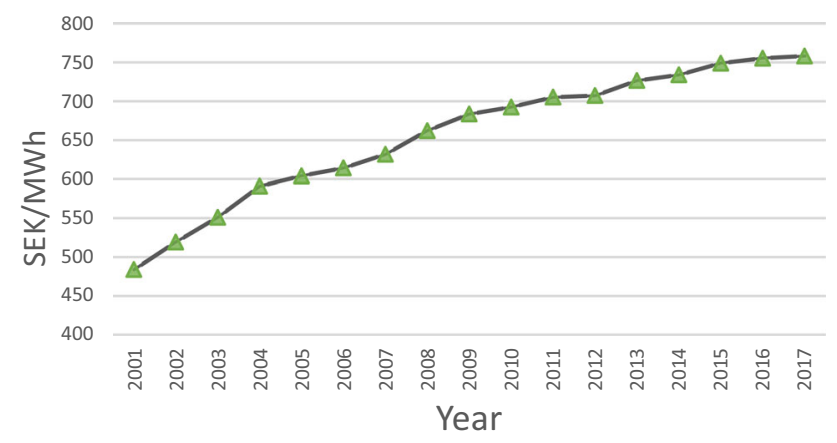

Fig. 1 Development of average DH price in Sweden 2001-2017 (Swedish Energy Agency)
The rest of the paper was organized as follows: Sect. 2 briefly reviewed the market-implemented price models of $\mathrm{DH}$, highlighted the knowledge gap and discussed the requirements on new price models; in Sect. 3, a new dynamic price model was proposed based on $\mathrm{LCOH}$ and hourly heat demand and two market-implemented price models and three alternative heating solutions were also described, which were used to analyze the influences of different price models; the result of price model comparison and the analysis of different alternative solutions under different price models were presented in Sect. 4; and the conclusions were summarized in Sect. 5.

\section{Issues regarding current price models of $\mathrm{DH}$}

\subsection{Pricing mechanism of $\mathrm{DH}$ and price model structure}

Pricing mechanism of DH has been reviewed in our previous work ( $\mathrm{Li}$ et al. 2015). There are two general methods: the cost-plus pricing method, which is often used in regulated DH markets and the marginal-cost pricing method, which is commonly used in deregulated heating markets.

Cost-plus pricing calculates the price as the sum of costs to be recovered and reasonable profits for DH companies. It offers a number of advantages to sellers, buyers, and regulators, such as simplicity, flexibility, and ease of administration. However, a regulated market does not encourage DH companies to compete with other heating solutions (Johns et al. 1982; Lassource 2013). The marginal-cost method is widely used in the deregulated market. Marginal cost is the cost of one more unit of product, which, in this case, is the cost of generating one more unit of heat through DH (Rolfsman and Gustafsson 2002; Trygg et al. 2009). In principle, the marginal-cost method reflects the scarcity of resources and it is considered as the basic method for determining the price of DH. However, when a DH company sets the price according to its marginal costs, which in turn largely depend on variable costs, the company may gain less profit than intended. This may lead to a lower interest in investment and maintenance (Westin and Lagergren 2002; Hansson 2009; Ericsson 2009).

The cost of a DH system depends on different factors, such as (1) the investment cost when customer joins the network, (2) the cost of a distribution network, which is determined by the size of the DH network and thermal loads, and (3) the production cost of thermal energy (Song et al. 2015). Therefore, in reality, the heat price is normally divided into different components to cover these costs. A comprehensive survey has been carried out about the marketimplemented price models in Sweden. 237 price models were investigated. Four typical components have been 
identified: (1) Fixed Connection Component (FCC) is the fee that a customer needs to pay each month for connecting to the network; (2) Flow Demand Component (FDC) is, in principle, charged on volume of hot water needed to deliver the heat that a customer consumes; (3) Load Demand Component (LDC) is charged to cover the investment and maintenance costs to maintain a certain level of heat capacity; and (4) Energy Demand Component (EDC) is charged to cover the fuel cost of heat production. In general, setting price based on marginal cost is only used to determine the component of EDC; and LDC and EDC account for more than $90 \%$ of the total expense of consumers. Among those four components, FCC and LDC can be considered as fixed costs while FDC and EDC can be considered as variable costs.

According to the survey, the investigated price models do not really reflect the production cost, which is largely dependent on the peak demand. In order to improve the competitiveness of $\mathrm{DH}$, some large companies have been reforming their price models and LDC receives the most attention. The purpose of emphasizing the importance of LDC is to encourage consumers to change their behavior and reduce the peak demand (Song et al. 2017). As a result, $\mathrm{DH}$ companies can reduce investments in peak capacity and avoid using expensive fuels, which would, consequently, lead to a lower heat price.

\subsection{Pricing dilemma}

\section{(1) Fixed cost versus variable cost}

One of the financial risks faced by $\mathrm{DH}$ companies is the high capital investment. A large share of operating costs is related to investment and maintenance cost on the $\mathrm{DH}$ system and does not vary according to the production; whereas, the heat production fluctuates largely over a year and between different years due to the variation of demand. Therefore, DH companies usually prefer a high share of fixed components in their price models to reduce such risks and streamline the cash flow. However, DH price model has moved toward a more consumer-oriented approach since the deregulation of $\mathrm{DH}$ market. Opposite to $\mathrm{DH}$ companies, consumers always prefer a high share of energy cost (variable cost), which facilitates energy conservation measures and increases price transparency. This means that the shares between fixed and variable costs in price models should be carefully determined to balance the need of producers and preference of consumers.

(2) Historic consumption data versus current heat demand

The level of LDC is usually determined according to the historical consumption data. However, the climatic condition changes year by year, resulting in a dynamic change of heat demand. Even though a correction based on the normal year can be introduced, there could still be a big deviation between the predicted and actual heat demand, since the demand is not totally depending on the yearly degree-day.

(3) Pricing transparency versus limited information accessibility

To ensure that the heat price on the wholesale market reflects the dynamics of supply and demand, market participants should be able to have access to the information on production and consumption. On the retail level, transparent information is important for consumers to choose the supplier as well as manage their energy consumption. Even though the legislative package in Europe plans various dispositions for consumer rights (Lassource 2013), and regulations have increasingly highlighted the importance of transparency for promoting trust and reducing complaints, there has been little work done to improve the transparency in $\mathrm{DH}$ system. DH companies keep claiming that they are using the marginal costs to determine heat prices, yet neither purchase price for fuels nor the production status in $\mathrm{DH}$ system is made available for consumers.

\subsection{Criteria for new price model}

Based on the discussion above, the DH price model should be able to:

- Reflect the dynamic production cost.

- Motivate consumers to reduce heat consumption, especially during the peak period of time.

- Be predictable.

- Be transparent and easy to understand.

To fulfill these criteria, a dynamic price model based on the prediction of system heat demand becomes more attractive, since it allows DH companies to predict the peak load more accurately and estimate the extra cost for covering the peak load. By charging a higher price for the peak, it even gives customers higher incentive to reduce the peak demand. Since heat production in Swedish DH systems is mainly from CHPs, a dynamic DH price model can also relate to the dynamic electricity price in a better way. Furthermore, a dynamic price model can improve the transparency, which has been proved to be an effective way to achieve higher energy savings in the domestic sector. By understanding the price model, customers can change their behaviors in order to reduce the heat consumption and save the cost. 


\section{Methodology}

In this paper, a dynamic price model was proposed based on LCOH. To estimate the capital cost and operation and maintenance costs (O\&M), a real DH company in Sweden was used as a case study. In order to consider the change in production methods, the heat demand was predicted by using neural networks. The proposed model was also compared two market-implemented price models (Song et al. 2015) to demonstrate its advantages. In addition, the impacts of price models on selecting alternative heating solutions were investigated, including heat pumps and direct electric heating.

\subsection{Proposed dynamic price model based on LCOH}

The levelized cost of energy is a popular methodology for evaluating the economic competitiveness of electricity generation technology over the long term (International Energy Agency 2015). Different from the marginal cost model, in which a fixed cost is charged on a period basis, the levelized cost approach uses the average cost of energy production over the lifetime of energy plant, which must take all fixed (investment, operations and maintenance, and decommissioning) and variable (fuel) costs into consideration. In the LCOH-based price model, the fixed cost is already integrated with variable cost. There is no need to include other fixed components. The main advantage of the LCOH-based method lies in its flexibility and transparency, while the biggest challenge for calculating $\mathrm{LCOH}$ is how to estimate the total heat production during the lifetime. LCOH-based prices are usually calculated on an hourly basis:

$$
\begin{aligned}
& \mathrm{LCOH}=\mathrm{LCOH}_{\text {fuel }}+\mathrm{LCOH}_{\mathrm{TIC}}+\mathrm{LCOH}_{\mathrm{O} \& \mathrm{M}} \\
& \mathrm{LCOH}_{\mathrm{TIC}}+\mathrm{LCOH}_{\mathrm{O} \& \mathrm{M}} \\
& =\frac{\sum_{t}\left(\mathrm{TIC}_{t}+\mathrm{FOM}_{t}+\mathrm{VOM}_{t}\right) \times(1+r)^{t}}{\sum_{t} \mathrm{HEAT}_{t}}
\end{aligned}
$$

where $\mathrm{LCOH}_{\text {fuel }}$ is the fuel cost to produce one unit of heat, TIC is the total investment cost, FOM and VOM are fixed operation and maintain cost and variable operation and maintain cost, respectively, $r$ is the interest rate, $t$ is the life span, and $\sum_{t} \mathrm{HEAT}_{t}$ is the total heat production during the life time.

For different production methods (bio-oil boilers, oil boilers, heat pumps, etc.), $\mathrm{LCOH}$ varies. When more than one production methods are used, the overall LCOH at a specific moment includes all costs for all methods in use and could be calculated via combining $\mathrm{LCOH}$ for each method according to their heat productions:
$\mathrm{LCOH}=\sum_{i=1}^{n}\left(\mathrm{LCOH}_{i} \frac{\text { Heat }_{i}}{\sum \text { Heat }_{i}}\right)$

where $n$ is the total number of methods for heat production and $i$ means the $i$ th method.

Since the CHP plant produces heat and power simultaneously, the fuel consumption should be allocated between electricity and heat production.

$F_{t}^{E}=\left(1-\alpha_{h}\right) \times$ Fuel cost

$F_{t}^{H}=\alpha_{h} \times$ Fuel cost

where $F_{t}^{E}$ and $F_{t}^{H}$ are the fuel costs for the electricity and heat productions, respectively, and $\alpha_{h}$ is the cost allocation factor.

There are a number of principles used to allocate joint costs between heat and power for CHP plants (Sjödin and Henning 2004; Tereshchenko and Nord 2015). The following three methods have been tested in this work:

M-1: Allocating the costs in proportion to the amounts of generated heat and electricity. This method is widely used due to the simplicity and accessibility of measurements. Energy taxation in Sweden also uses this method as the ground on CHP plants. But it does not consider the energy quality difference between heat and electricity, in other words, it tends to allocate less fuel on electricity and more on heat. Since the efficiency of CHP plant to produce electricity and heat was assumed to be same in this study, the total fuel costs can be allocated between heat and electricity according to the electricity-to-heat ratio.

M-2: Allocating the costs in proportion to the exergy of the generated heat and electricity. This method is based on the second law of thermodynamics, which reflects the quality of electricity and heat. Since electricity is better than heat in quality, this method will normally allocate a higher share of costs on electricity generation. The exergy of electricity is equal to its energy, while the exergy of heat can be calculated as:

Exergy $_{H}=$ Energy $_{H} \times \frac{T_{H}-T_{\mathrm{a}}}{T_{H}}$

where $T_{H}$ is the temperature of supply water $(\mathrm{K})$ and $T_{\mathrm{a}}$ is the ambient temperature $(\mathrm{K})$.

M-3: Allocating all costs on heat production with the deduction of the income of selling electricity. Since the deregulation of energy market, the electricity price depends totally on bidding in the market, while energy companies maintain autonomy on price of heat. In this method, electricity is considered as by-product. All fuel cost is allocated on heat, and after deducting the income from selling electricity from the total cost, the heat price can be determined. 
As aforementioned, the fuel allocation should only be applied to the fuel used in cogeneration process of heat and electricity. In practice, CHP plants are not always operated in the cogeneration mode. As shown in Fig. 2, when heat demand reaches a high level, the turbine is bypassed to produce more heat. The fuel used in the bypass process should not be divided between heat and electricity, as it is used only for heat production (HO). In order to accurately allocate the cost between heat and electricity production, heat produced in the CHP system can be further divided into heat produced from the cogeneration mode (H_CHP) and heat produced from heat-only mode (H_HO). Meanwhile, some heat can be recovered from Flue Gas Condensation (H_FGC) at high heat demand. Such heat is usually released to the ambient and not included in the heat production of CHP. Therefore, the fuel cost of H_FGC was considered negligible in the calculation.

$\mathrm{LCOH}$ is tightly related to the level of heat demand, which determines the methods used for heat production. Once the heat demand is known, the involved heat production methods are known, and then LCOH could be calculated by Eq. 3 .

The calculation of $\mathrm{LCOH}$ in this paper was based on a real DH system, which consists of a CHP plant, a biomass boiler, and a bio-oil boiler. Detailed input data and assumptions are listed in Table 1.

Figure 3 shows the total heat production and the breakdown for each specific method. CHP is the primary method, which is usually scheduled to shut down for maintenance for 1 month in summer, while biomass boiler is used as an alternative. Since the oil price is high, the oil boiler is only running during very cold days, when the production from other methods cannot cover the total heat demand.

\subsection{Prediction of heat demand}

An accurate prediction of heat demand is important in the calculation of LCOH. In our previous work (Ma et al. 2014; Xie et al. 2017), a model based on Elman neural networks $(\mathrm{ENN})$ is developed to predict the heat demand.
Table 1 Input data and assumptions

\begin{tabular}{lll}
\hline Parameter & Unit & Value \\
\hline CHP plant & & \\
CHP boiler & MWth & 150 \\
Steam turbine (ST) & MWe & 39 \\
Designed heat to power ratio & & 1.82 \\
Min partial load of ST & $\%$ & 25 \\
FGC & MWmax & 32 \\
Boiler efficiency & $\%$ & 85 \\
CHP TIC & MSEK & 108.9 \\
Operating hour of CHP & h & 7500 \\
Biomass plant & & \\
Biomass boiler & MWth & 66 \\
Biomass boiler TIC & MSEK & 33 \\
Bio-oil plant & & \\
Bio-oil boiler & MWth & 24 \\
Bio-oil boiler TIC & MSEK & 17.8 \\
Fuel price & & \\
Biomass price & SEK/kWh & 0.18 \\
Bio-oil price & SEK/kWh & 0495 \\
Electricity price & SEK/MWh & 26.1 \\
Other & & \\
Lifespan & year & 20 \\
Interest rate & $\%$ & 8 \\
Profit & & \\
\hline
\end{tabular}

The model of Elman neural network is presented as follows:

$x_{1}(k)=f\left[w^{1} u(k-1)+w^{c 1} x_{c 1}(k)\right]$

$x_{i}(k)=f\left[w^{i} x_{i-1}(k-1)+w^{c i} x_{c i}(k)\right], \quad i=2,3, \ldots, s$

$x_{c i}(k)=x_{i}(k-1), \quad i=2,3, \ldots, s$

$y(k)=g\left[w^{s+1} x_{s}(k)\right]$

where $s$ is number of hidden layers, $u(k)$ is the input of the model, $x_{c i}(k)$ and $x_{i}(k)$ are the output of context layer $i$ and hidden layer $i, y(k)$ is the output of output layer, $w^{1}$ is the

Fig. 2 Energy flow in a CHP system

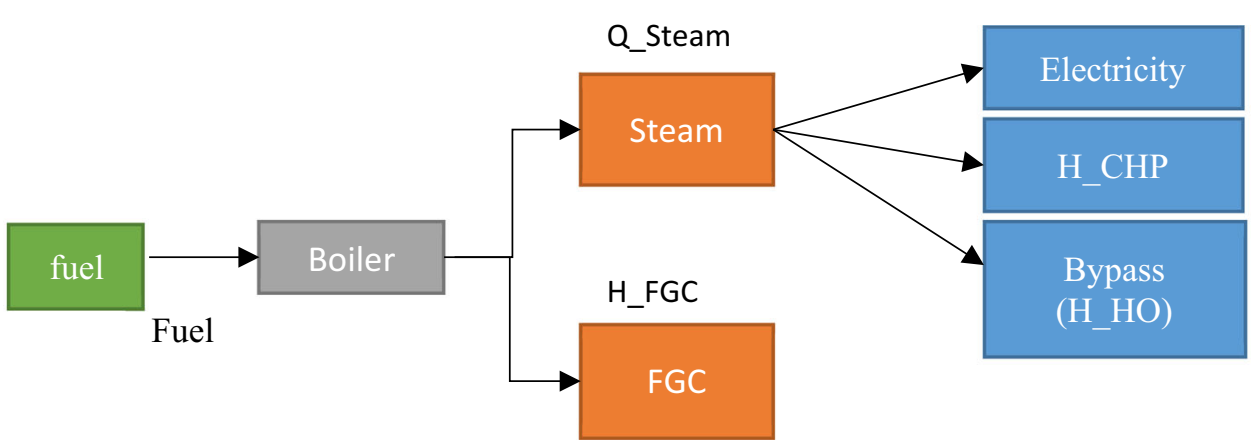


Fig. 3 Heat productions from different plants

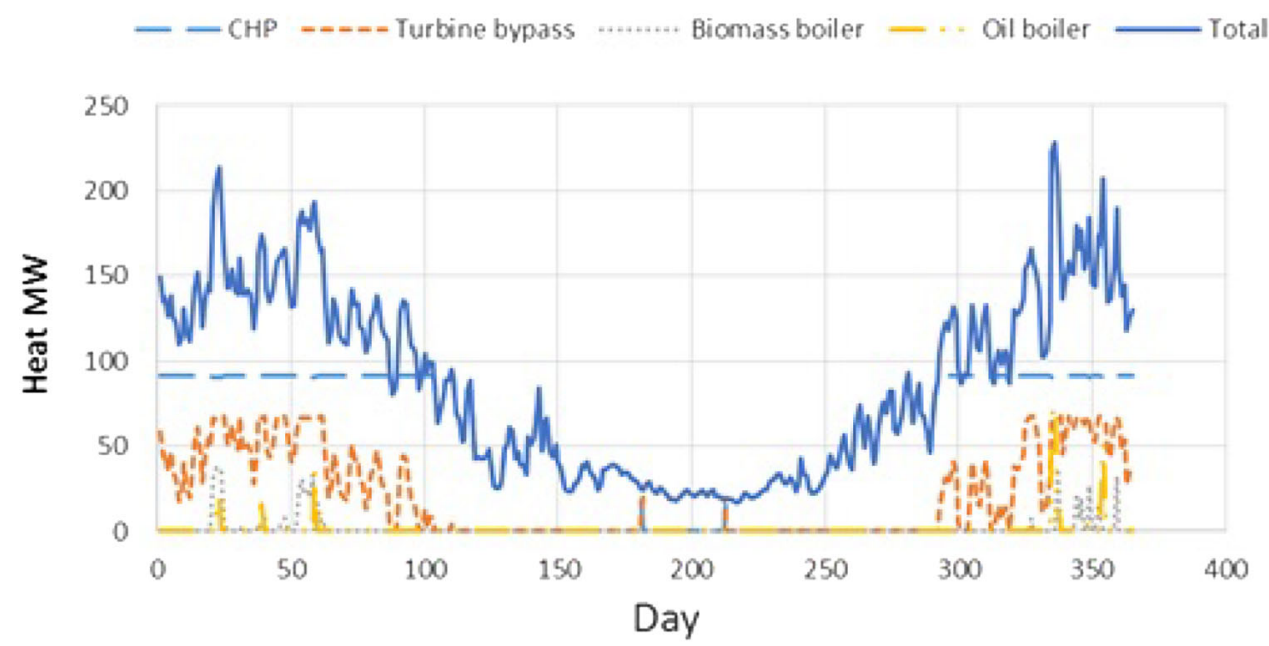

connection weight matrix between the input layer and the hidden layer $1, w^{i}$ is the connection weight matrix between the hidden layer $i$ and the hidden layer $(i-1), w^{n+1}$ is the connection weight matrix between the hidden layer $n$ and the output layer, respectively, $w^{c i}$ is the connection weight matrix between the hidden layer $i$ and the context layer $i$. $f(\cdot)$ and $g(\cdot)$ are transfer functions, $f(\cdot)$ is usually sigmoid, tangent sigmoid, or logarithm sigmoid transfer function and $g(\cdot)$ is usually a linear transfer function. More detailed information about the developed model is given in (Ma et al. 2014; Xie et al. 2017). Comparing the predicted heat demand with the operation statistics obtained from the $\mathrm{DH}$ company, the overall mean absolute percentage error (MAPE) was $4.43 \%$, which indicated that the prediction model worked well in this case.

MAPE $=\frac{1}{n} \sum_{i=1}^{n} \frac{\left|y_{i}-y_{\mathrm{pi}}\right|}{y_{i}} \times 100 \%$

where $y_{i}$ is the actual heat demand value, $y_{\mathrm{pi}}$ is the corresponding heat demand prediction value, and $n$ is the prediction step length.

\subsection{Market-implemented price models}

Different from the LCOH-based price model, DH companies use other models. In this work, two market-implemented models identified from the previous price model survey (Song et al. 2015) were included for comparison purpose.

\subsubsection{Seasonal price model (Old-PM)}

Seasonal Price model has been widely adopted. The LDC in this model is based on customers' highest measured daily average demand in 1 year, and the EDC consisted of two levels of seasonal energy price (higher during winter and lower during summer) to differentiate consumptions in different periods.

Under this model, a customer's DH cost is expressed as:

$E=P_{\text {energy.w }} \times C_{\mathrm{w}}+P_{\text {energy.s }} \times C_{\mathrm{s}}+P_{\text {load }} \times L_{\text {peak }}$

where $P_{\text {energy.w }}$ is the energy price during winter season, $P_{\text {energy.s }}$ is the energy price during summer season, $C_{\mathrm{w}}$ is customer's winter DH consumption, $C_{\mathrm{s}}$ is customer's summer DH consumption, $P_{\text {load }}$ is the load demand price, and $L_{\text {peak }}$ is customer's peak demand (daily).

\subsubsection{Subscription price model (New-PM)}

Subscription price model is a newly emerged price model. Similar to the seasonal price model, the LDC in this model is also based on the peak demand of customers, except it is on hourly basis instead of daily basis. The EDC is based on customers instant demand level. The DH company suggests a subscription level in proportion to the customer's peak load demand, and customers pay a relatively lower price (so-called base price) for their heat consumption below the subscription level, but a relatively higher price for the part above the subscription level (so-called peak price).

A customer's cost is calculated as:

$E=P_{\text {energy.b }} \times C_{\mathrm{b}}+P_{\text {energy.p }} \times C_{p}+P_{\text {load }} \times L_{\text {peak }} \times \alpha$

where $P_{\text {energy.b }}$ is base energy price, $P_{\text {energy.p }}$ is peak energy price, $C_{\mathrm{b}}$ is the heat consumption below the subscription level, $C_{p}$ is customer's heat consumption above the subscription level, $P_{\text {load }}$ is load demand price, $L_{\text {peak }}$ is customer's peak demand (hourly), $\alpha$ is the subscription level, which equals to the share of base load plant's capacity in comparison with the total capacity in the DH system.

Both Old-PM and New-PM consist of a LDC and an EDC; and the specific price levels for each model are listed 
in Table 2. Neither Old-PM nor New-PM is dynamic price model. To calculate the hourly price for the implemented models, 638 customers' consumption data were collected from the local energy company. Each customer's hourly costs on EDC were calculated according to the energy consumption and the energy price level during that hour. The annual cost on LDC was first calculated based on the customer's peak demand and the load price level, and then evenly distributed into each hour of the year. The average hourly $\mathrm{DH}$ price then was calculated by adding up each customer's hourly cost on both EDC and LDC and then divided by the total $\mathrm{DH}$ consumption during that hour.

\subsection{Different alternative heating solutions to $\mathrm{DH}$}

It is more likely for a customer to take action if the cost increases significantly. In order to assess the impacts of price models on the selection of alternative heating solutions, an industry customer facing significant cost increase in the price model restructuring process was selected according to our previous work (Song et al. 2017). The annual heating cost of the selected customer was calculated by applying different price models.

Three alternative solutions to lower the energy expense were considered in this study: using DH and direct electrical heating $(\mathrm{DEH})$ to provide the base and peak heating demands; using ground source heat pump (HP) and DH to provide base and peak demands, and using HP and DEH to provide base and peak demands; Fig. 4 shows the selected customer's consumption profile for different alternatives. The annual cost of each solution is the sum of DH cost, electricity cost, and annual investment cost for $\mathrm{HP}$ and DEH installation.

The capacity of HP was dimensioned to achieve the optimal annual cost. It was assumed that the capital investment of heat pump was 15,000 SEK/kW (Björk et al. 2013), the lifespan was 20 years, and the interest rate was $5 \%$ (Statistics Sweden \& the Swedish Central Bank). The annual investment cost of HP could be calculated by Eq. 14; the annuity of investment was 1990 SEK/
(kW year). The seasonal COP of heat pump was assumed to be 3.5 and the price of electricity was $840 \mathrm{SEK} / \mathrm{MWh}$ (Statistics Sweden \& Swedish Energy Agency). The cost of implementing direct electrical heating equipment was negligible compared to life span of 20 years.

$C_{\text {annual }}=\frac{I_{\text {cap }} \times(1+a)^{L}}{L}$

where $C_{\text {annual }}$ is the annual investment cost per installed capacity of heat pump, $I_{\text {cap }}$ is capital investment of heat pump, $a$ is interest rate of capital, and $L$ is life span of heat pumps.

\section{Results}

\subsection{Comparison of proposed and implemented price models}

Figure 5 shows the LCOH with different levels of heat demand. In general, there was a clear drop; no matter which method is used for allocating the fuel cost for CHP. The drop happened at the moment when FGC was involved in heat production. Since the fuel cost in FGC was negligible, when the total cost remained the same, while more heat were produced, it leaded to a lower cost per unit of heat production. For M-1 and M-2, LCOH went up when the turbine was bypassed, due to more fuel allocated for heat production as electricity production was lowered. For $\mathrm{M}-3$, due to the high fraction of the capital cost in $\mathrm{LCOH}$, H_CHP has a higher cost than H_HO. Therefore, when the turbine was bypassed, heat production in the heat-only cycle increased, whereas, the production in the CHP cycle decreased, resulting in decrease of $\mathrm{LCOH}$.

Figure 6 shows the variation of heat demand and price from different price models through 1 year time. In general, LCOH-based models reflect the variation of heat demand in a better way and effectively cover the high cost at the peaks. It was also interesting to see that the prices at low heat demands, for example in summer, were still quite
Table 2 Price levels of price models in use

\begin{tabular}{lr}
\hline Seasonal model (Old-PM) & \\
\hline Price level for energy demand component in summer (SEK/MWh) & 253 \\
Price level for energy demand component in winter (SEK/MWh) & 455 \\
Price level for load demand component (SEK/kW) & 560 \\
\hline Subscription model (New-PM) & 369 \\
\hline Price level for energy demand component base $(\mathrm{SEK} / \mathrm{kWh})$ & 1386 \\
Price level for energy demand component peak $(\mathrm{SEK} / \mathrm{kWh})$ & 729 \\
Price level for load demand component $(\mathrm{SEK} / \mathrm{kW})$ &
\end{tabular}


Fig. 4 Consumption profile of different heating solutions
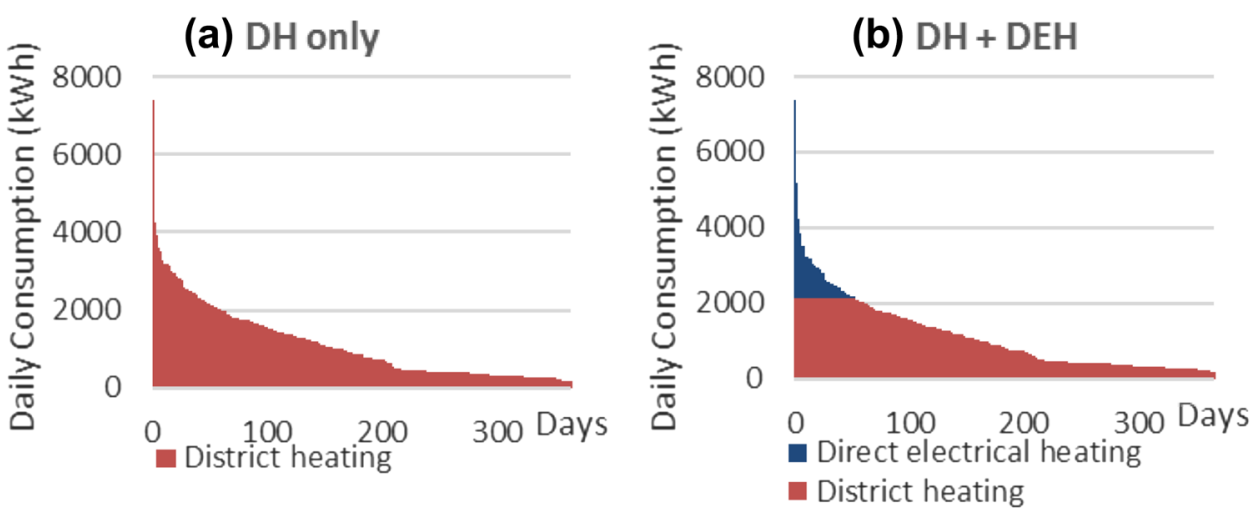

(c) $\mathrm{HP}+\mathrm{DH}$

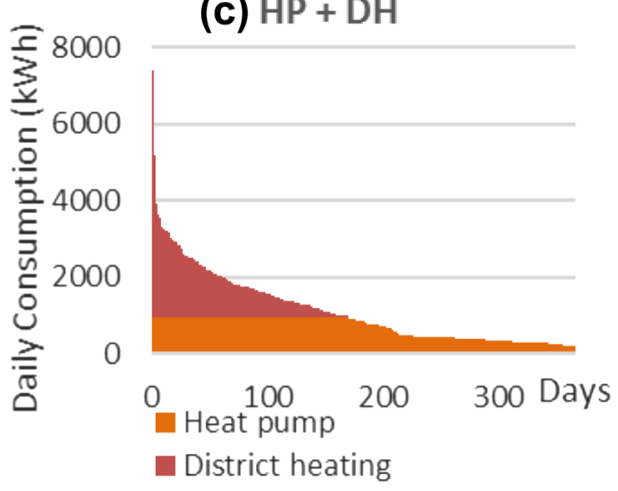

(d) HP + DEH

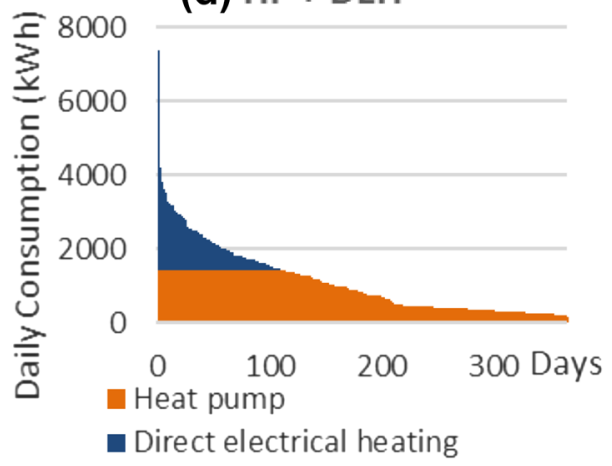

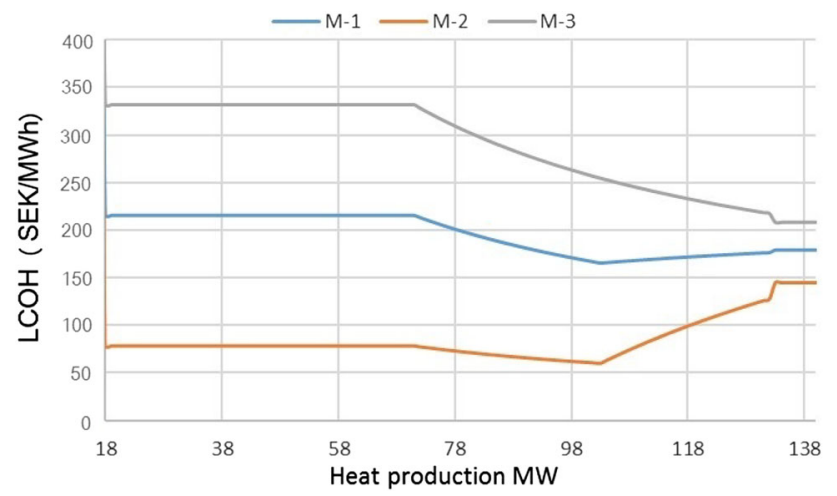

Fig. 5 Variation of LCOH with different levels of heat demand

high for the proposed dynamic models; since CHP was shut down during summer and the biomass boiler was used instead, the high fuel price resulted in a high DH price.

For the two market-implemented price models, the high price during summer time was majorly due to the fixed LDC, which was not allocated according to the energy consumption but based on time.

Table 3 compares the characters of different price models. In general, Old-PM is simple to understand. As the seasonal based EDC accounts for the major part of the heat price, it can also reflect the dynamic production cost. For New-PM, the average price depends largely on the peak demand of customers. Therefore, it can effectively motivate customers to reduce the peak load. Yet, such a model is difficult to understand and is less transparent. For the price models based on $\mathrm{LCOH}$, the price varies with the production cost, which is further determined by the demand; hence, it can motivate customers to reduce the heat consumption, especially during the peak time. It is easier to understand, but the complexity of calculation results in uncertainties of the cost.

\subsection{Influences of price models on heat expenses}

To demonstrate the influence of price models on the heat expense of customers, the expenses were calculated for all types of building (office \& school, commercial buildings, hospital \& social service buildings, and industry buildings) under different price models. Results show quite similar trend. Therefore, a user of multifamily house was chosen as an example. Figure 7 shows the heat demand and hourly heat expense. In general, the expense changed along with heat demand regardless of price model. Comparatively, the expense under the dynamic models varies in a more obvious way than under the two market-implemented price models (Old-PM and New-PM). The proposed dynamic price models resulted in a higher cost than the marketimplemented price models when the demand was at a higher level, and the difference increased along with the peak demand. Nevertheless, in most of the time, the 
Fig. 6 Heat price from different price models at different heat demands

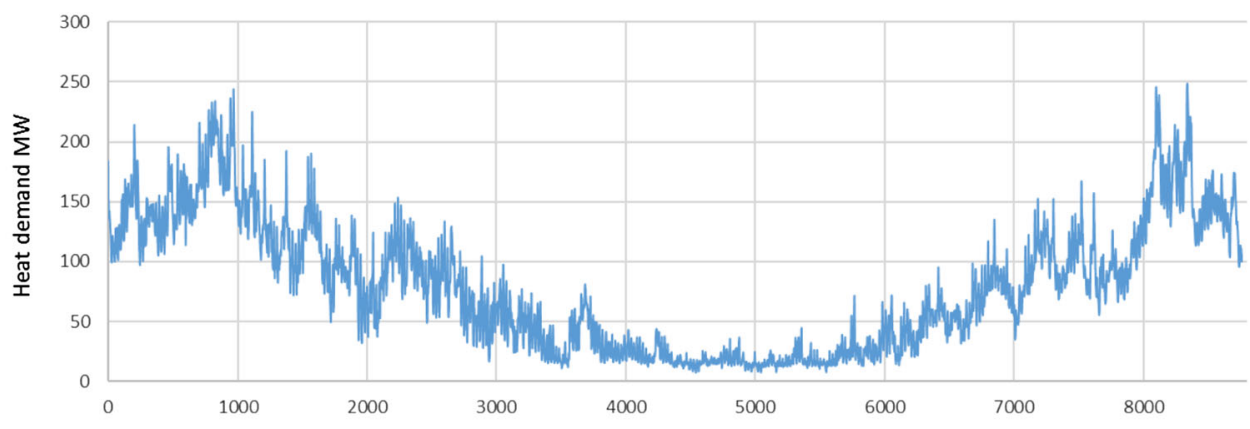

(a) Dynamic heat demand in the studied DH network

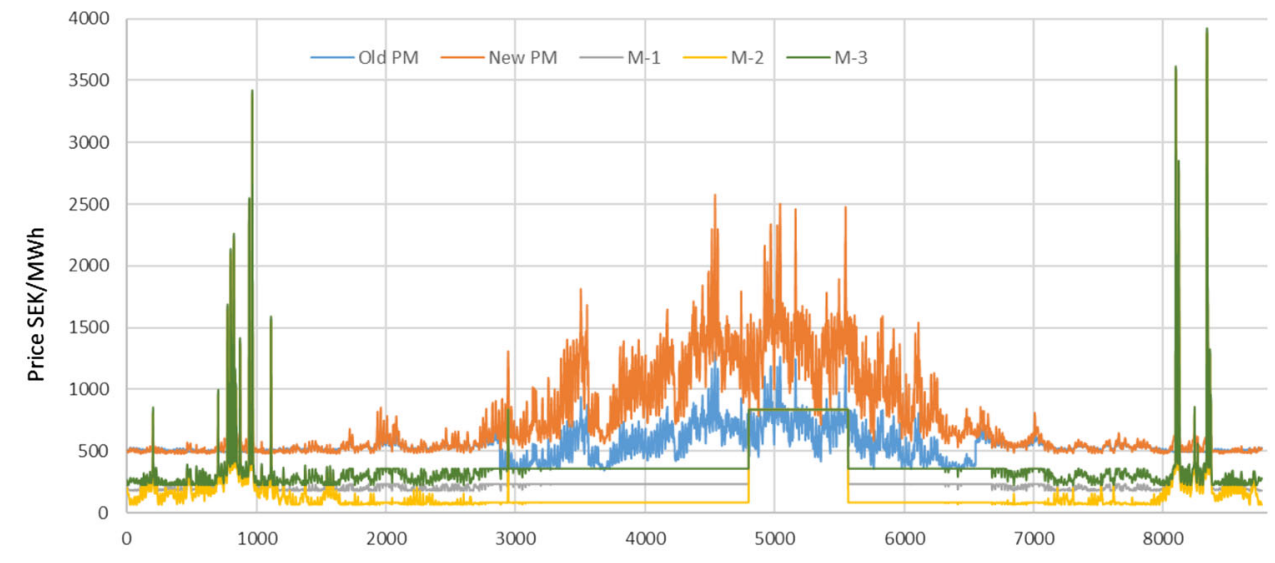

(b) Variation of heat price with heat demand

Table 3 Characters of different price models

\begin{tabular}{|c|c|c|c|}
\hline & $\begin{array}{l}\text { Old-PM (seasonal } \\
\text { fuel cost) }\end{array}$ & $\begin{array}{l}\text { New-PM (subscribed } \\
\text { heat capacity) }\end{array}$ & $\begin{array}{l}\text { LCOH-based PM (e.g., M-1, } \\
\text { M-2, and M-3) }\end{array}$ \\
\hline Simplicity & ++ & - & - \\
\hline Predictability & - & - & + \\
\hline Transparency & + & -- & + \\
\hline Reflecting the dynamic production cost & + & + & ++ \\
\hline Reflecting the dynamic heat demand & -- & - & ++ \\
\hline Motivate customers to reduce the peak load & - & ++ & ++ \\
\hline Motivate customers to save energy & + & - & ++ \\
\hline
\end{tabular}

expenses under dynamic price models were lower than those under the market-implemented price models. It implies the proposed dynamic model could have a bigger potential in motivating the customers to reduce the peak load.

\subsection{Influences of price models on alternatives of $\mathrm{DH}$}

The costs of using DH only and other three alternatives were calculated based on the consumption data of the same customer (industry buildings). The annual costs of each solution under different price models were shown in Fig. 8.
For the two market-implemented price models (Old-PM and New-PM), installing heat pump to supply base demand and using district heating to cover the peak demand was not an attractive solution, since it only marginally reduced the annual cost (by $4 \%$ and $1 \%$, respectively), but exposed the consumer to a higher risk due to the extra investment cost. Reducing the peak demand of $\mathrm{DH}$ with direct electrical heating $(\mathrm{DEH})$ can reduce the cost by $31 \%$ and $39 \%$, respectively, under these two models, which makes it the second best solution under both implemented models. Installing a heat pump and using DEH to cover the peak demand was the best alternative, which can reduce the 
Fig. 7 Heat demand and expenses of a multifamily house
Fig. 8 Cost comparison between Old-PM, New-PM, M-1, M-2 and M-3 for different alternative solutions $(\mathrm{DH}$ district heating cost, $H P$ investment for heat pump, $E l$ electricity cost)
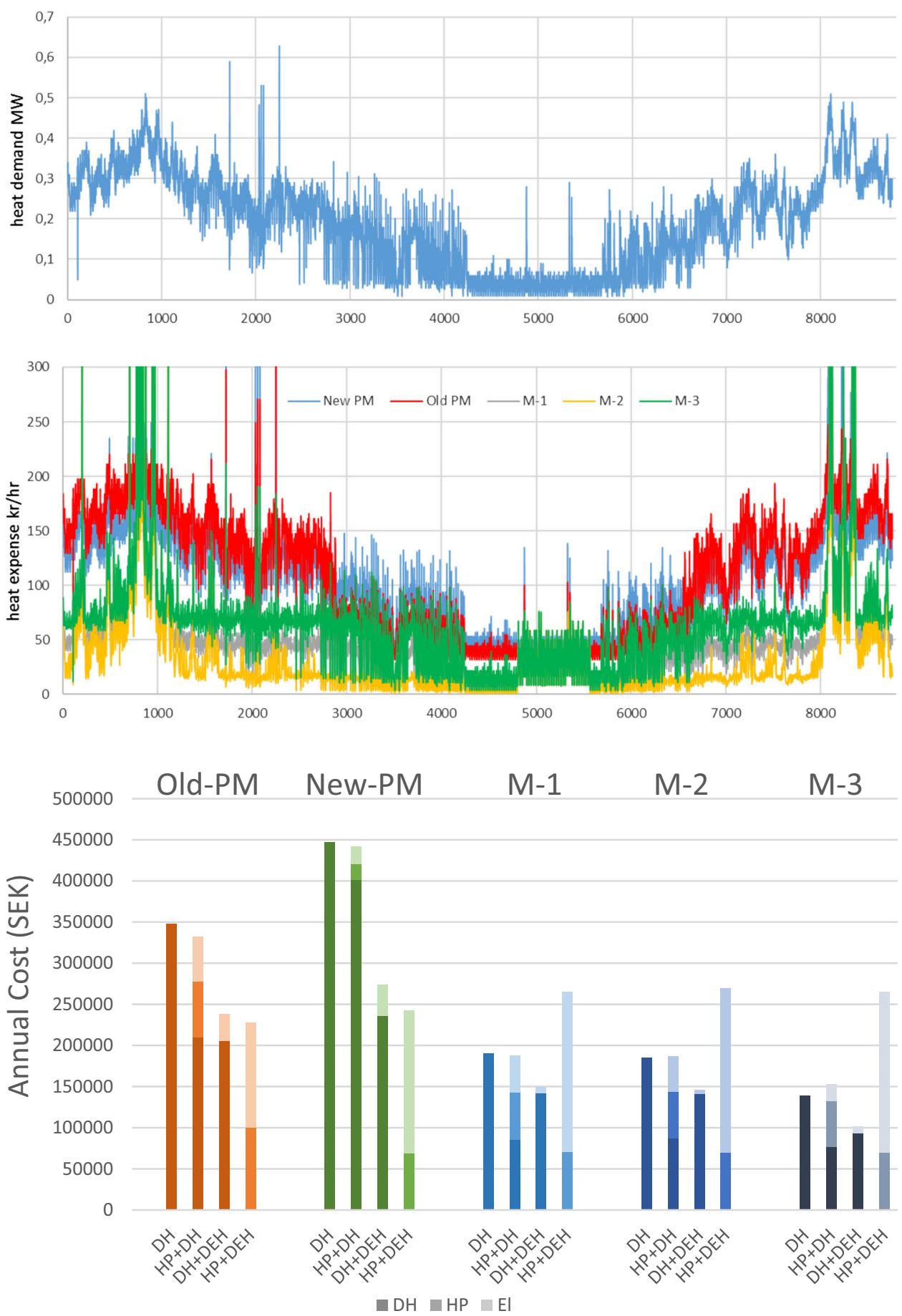

annual cost by $35 \%$ and $46 \%$, respectively. For the dynamic model based on $\mathrm{LCOH}$, since a much lower heat price could be obtained, the alternatives do not show as much saving as under the market-implemented price models. Using DEH to cover the peak demand of DH was instead the most economical alternative. Moreover, installing a heat pump and using direct electrical heating to cover the peak was not lucrative at all.

\section{Conclusion}

District heating (DH) companies are facing several challenges in the current heat market. In this paper, a novel dynamic price model based on the levelized cost of heat $(\mathrm{LCOH})$ was proposed in order to improve the competence of district heating. The proposed model carefully considered the capital cost, operation and maintenance cost as 
well as other costs. The following conclusions can be drawn:

- The prices based on LCOH can be lower than those from the market-implemented price models. The variation of $\mathrm{LCOH}$ followed the fluctuation of heat demand, and therefore, the proposed model can demonstrate the production cost more accurately, whereas, the complexity of the proposed model, for example to allocate the cost between heat and electricity in a CHP plant, might hinder its feasibility. Meanwhile, the dynamic operation hours of equipment and unpredictable maintenance cost could also introduce large deviations in the calculation of $\mathrm{LCOH}$.

- At peak demands, the dynamic model can result in an even higher hourly price than the market-implemented price models, which implies that the dynamic model may have a bigger potential to motivate consumers to reduce the peak load.

- Price model reforming could lead to a significant change in the expense of consumers and affect the selection of alternatives to $\mathrm{DH}$ by investigating the influences of price models on the heat expenses of consumers; it was found that installing a heat pump and using direct electric heating (DHE) to cover the peak demand and using DEH to cover the peak demand of DH were the most economical alternatives under the market-implemented price models and the proposed dynamic price model, respectively.

Acknowledgements The financial support from Energimyndigheten and Energiforsk AB (Fjärrsynsprojekt 5334: Dynamisk prismekanism), Project U1864202 supported by National Natural Science Foundation of China and the Fundamental Research Funds of Shandong University 2018JC060 is gratefully acknowledged.

Open Access This article is distributed under the terms of the Creative Commons Attribution 4.0 International License (http://crea tivecommons.org/licenses/by/4.0/), which permits unrestricted use, distribution, and reproduction in any medium, provided you give appropriate credit to the original author(s) and the source, provide a link to the Creative Commons license, and indicate if changes were made.

\section{References}

Björk E, Acuña J, Granryd E, Mogensen P, Nowacki J-E, Palm B, Weber K (2013) Geothermal in depth: the book for you who will know more about geothermal heat pumps (in Swedish). In: Bergvärme på djupet: boken för dig som vill veta mer om bergvärmepumpar. US-AB, Stockholm
DHC + Technology Platform (2012) District heating and cooling: a vision towards 2020-2030-2050. Euroheat \& Power, Brussels

Difs K, Trygg L (2009) Pricing district heating by marginal cost. Energy Policy 37:606-616

Ericsson K (2009) Introduction and development of the Swedish district heating systems: critical factors and lessons learned. Lund University, Lund

Hansson J (2009) The Swedish district heating market. Uppsala University, Uppsala

International Energy Agency (2015) Projected costs of generating electricity. IEA, Paris

International Energy Agency (2018) Key world energy statistics. IEA, France

Johns LS, Rowberg RE, Procter ME, Bazques E, Goldberg B, McGrill D, Seder J, Naismith N (1982) Energy efficiency of buildings in cities. Government Printing Office, Washington, DC

Lassource A (2013) European energy markets transparency report2013 edition. European University Institute, Florence

Li H, Sun Q, Zhang Q, Wallin F (2015) A review of the pricing mechanisms for district heating systems. Renew Sustain Energy Rev 43:56-65

Lin H, Wang Q, Wang Y, Liu Y, Sun Q, Wennersten R (2017) The energy-saving potential of an office under different pricing mechanisms - application of an agent-based model. Appl Energy 202:248-258

Ma Z, Li H, Sun Q, Wang C, Yan A, Starfelt F (2014) Statistical analysis of energy consumption patterns on the heat demand of buildings in district heating systems. Energy Build 85:464-472

Rolfsman B, Gustafsson S-I (2002) Energy conservation conflicts in district heating systems. Int J Energy Res 27(1):31-43

Sjödin J, Henning D (2004) Calculating the marginal costs of a district-heating utility. Appl Energy 78:1-18

Song J (2017) District heating cost fluctuation caused by price model shift. Appl Energy 194:715-724

Song J, Wallin F, Li H, Karlsson B (2015) Price models of district heating in Sweden. Energy Proc 88:100-105

Statistics Sweden \& Swedish Energy Agency. Energy prices on natural gas and electricity. http://www.scb.se/en0302-en. Accessed 31 Oct 2018

Statistics Sweden \& The Swedish Central Bank. Short-term and longterm interest. http://www.scb.se/sv_/Hitta-statistik/Statistikefter-amne/22678/Allmant/Sveriges-ekonomi/Aktuell-Pong/31243/ EK0204/32290/\#. Accessed 27 Oct 2018

Swedish Energy Agency. Database: district heat price. http:// pxexternal.energimyndigheten.se/pxweb/en/Tr\%C3\%A4dbr\% C3\%A4nsle-\%20och\%20torvpriser/Tr\%C3\%A4dbr\%C3\%A4nsle-\% 20och\%20torvpriser/EN0307_4.px/table/tableViewLayout2/?rxid= d04d3e27-62f1-4919-9746-41747dd03519. Accessed 30 Oct 2018

Tereshchenko T, Nord N (2015) Uncertainty of the allocation factors of heat and electricity production of combined cycle power plant. Appl Therm Eng 76:410-422

Wang Y, Lin H, Liu Y, Sun Q, Wennersten R (2018) Management of household electricity consumption under price-based demand response scheme. J Clean Prod 204:926-938

Westin P, Lagergren F (2002) Re-regulating district heating in Sweden. Energy Policy 30:583-596

Xie J, Li H, Ma Z, Sun Q, Walllin F, Si Z, Gao J (2017) Analysis of key factors in heat demand prediction with neural networks. Energy Proc 105:2965-2970 